Gut, 1973, 14, 116-119

\title{
The effects of vagotomy on the intestinal handling of water and electrolytes
}

\author{
G. A. BUNCH ${ }^{1}$ AND R. SHIELDS \\ From the Royal Infirmary, Cardiff
}

SUMMARY A technique of intestinal perfusion has been used to investigate the effects of vagotomy on the intestinal handling of water and electrolytes. The capacity of the vagotomized jejunum to absorb water and electrolytes was found to be unimpaired, even in patients who had severe postvagotomy diarrhoea.

Diarrhoea is well recognized as a cause of morbidity after the operation of vagotomy and gastric drainage for duodenal ulceration. Diarrhoea may be said to represent the malabsorption of water and electrolytes, and in spite of a great deal of investigation the cause of this diarrhoea remains unexplained. The possibility that a defect in the ability of the intestine to absorb water and electrolytes may explain this diarrhoea has been investigated, and in this paper we report on the intestinal handling of water and the principal electrolytes-sodium and potassium-immediately after operation when the effects of vagotomy might be expected to be maximal and later, in patients with and without severe postvagotomy diarrhoea.

\section{Patients Studied}

Successful studies were performed upon 25 subjects; nine of these were patients undergoing truncal vagotomy and nine were patients undergoing cholecystectomy. Of these 18 patients, all except one of them were studied twice immediately after operation, first at six hours and again between 24 and 30 hours after operation.

Of the nine patients undergoing vagotomy, three were studied on the day before operation and four of the patients undergoing cholecystectomy were also studied on the day before operation. Additional control data were obtained from four healthy volunteer subjects not undergoing surgery; one of these was studied on two occasions, giving a total of 12 control, or contrast studies. These contrast studies are assumed to represent normal absorption before operation.

'Please address requests for reprints to Mr G. A. Bunch, The Royal Infirmary, Huddersfield.

Received for publication 6 December 1972.
After the 10th postoperative day, three patients who had had a vagotomy were studied and three patients with severe postvagotomy diarrhoea who passed frequent, watery stools daily were also studied.

\section{Technique of Study}

Patients were studied using a technique of intestinal perfusion similar to that described by Phillips and Summerskill (1966). The principle of the method is that a segment of small intestine is perfused with a test solution of known composition. At the end of the test segment the perfusate is sampled by aspiration and analysed. From the change occurring in the volume and composition of the test solution during its passage through the test segment, the rate of absorption from the segment can be calculated.

A double-lumen tube, suitably modified (Fig.), was passed through the nose until it reached the upper jejunum. The position of the tube was ascertained by radiographic screening. The proximal balloon ( $\mathrm{C}$ in the figure) was sited just beyond the duodeno-jejunal flexure.

The test solution was modified Tyrode's solution containing $\mathrm{Na}^{+}-149 \mathrm{~m}$-equiv/1, $\mathrm{K}^{+}-3 \cdot 3 \mathrm{~m}$-equiv/1, $\mathrm{Cl}^{-}-143$ m-equiv/1, $\mathrm{HCO}^{-}{ }_{3}-12 \mathrm{~m}$-equiv/1, and glucose $0.9 \mathrm{~g} / 1$ (Code and MacIntyre, 1956). The non-absorbed marker polyethylene glycol (PEG) was added at a concentration of $1 \% \mathrm{w} / \mathrm{v}$ as a volume indicator and the solution was brought to $\mathrm{pH} \mathrm{7.0}$ by the addition of $0.1 \mathrm{~N} \mathrm{HCl}$. Isotopes of sodium, potassium, and water were added in tracer quantities $\left({ }^{24} \mathrm{Na} 2 \mu \mathrm{c} / 1,{ }^{42} \mathrm{~K} 4 \mu \mathrm{c} / 1, \mathrm{D}_{2} \mathrm{O}, 1 \% \mathrm{vol} / \mathrm{vol}\right)$ to allow calculation of the two-way traffic across the mucosa.

The test solution was warmed to $37^{\circ} \mathrm{C}$ and instilled into the intestine at about $10 \mathrm{ml} / \mathrm{min}$ through the infusion lumen (A) of the perfusion 


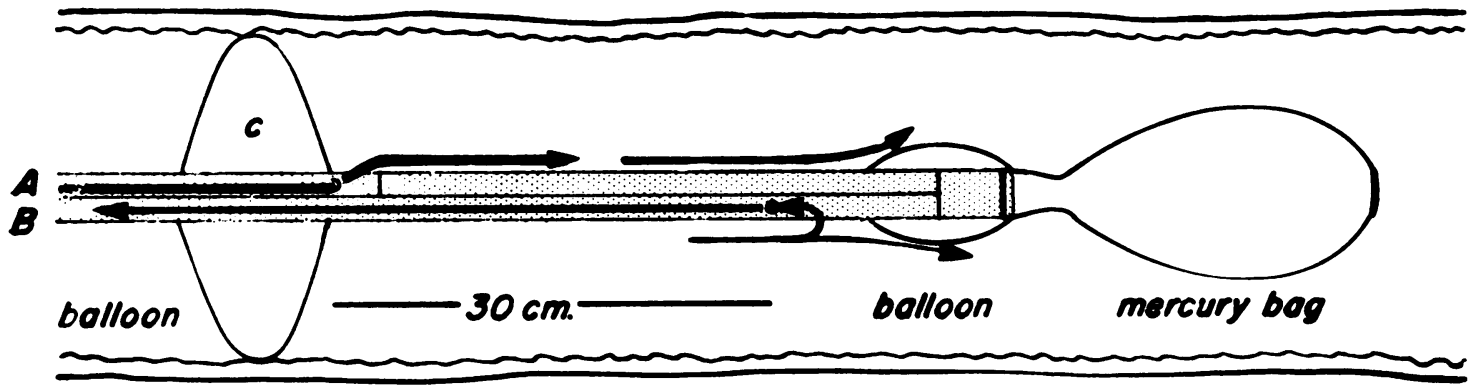

Fig. 1 The tube was constructed from double-lumen tubing (Portex MLT-B). A proximal inflatable balloon (C) and a distal inflatable balloon (to aid intestinal transit) were attached. Air could be introduced into these balloons as required through fine polythene tubes (Portex pp25) sealed into the main tube.

The two main lumens of the tube communicated with the intestine $30 \mathrm{cms}$ apart through holes cut into them and acted as inflow lumen $(A)$, for the test solution and outflow lumen $(B)$, for the perfusate.

The proximal balloon $(C)$ was inflated during the perfusion study to prevent reflux of test solution out of the test segment and contamination of the segment by fasting content. The distal balloon was only inflated to aid intestinal transit.

tube (Fig.) by means of a pump. An equilibration period of 40 minutes was allowed and then sampling by siphonage was begun from the outflow lumen (B). A number of aliquots of perfusate (usually six) were collected from each patient.

Each freshly prepared test solution and each aliquot of perfusate was analysed for PEG, sodium, potassium, and $\mathrm{D}_{2} \mathrm{O}$ concentration, and ${ }^{24} \mathrm{Na}$ and ${ }^{42} \mathrm{~K}$ activity as previously described (Shields, 1966). Calculation of the transport rates was from the formulae set out by Shields (1966).

\section{Results}

The results are recorded in the Table.

\section{IMMEDIATE EFFECTS}

We have previously reported the changes that occur in the intestinal handling of water and electrolytes immediately after operation (Bunch and Shields, 1969). Because of the differences we observed between those patients receiving intravenous fluids and those patients deprived of them, intravenous fluids were given to four patients after vagotomy and three patients after cholecystectomy. These patients received 1 litre of Hartmann's solution and 1.5 litre dextrose solution $(5 \% \mathrm{w} / \mathrm{v})$ on the day of operation and 1 litre Hartmann's solution and 2 litres dextrose solution on the first postoperative day. The remaining patients received only $500 \mathrm{ml}$ Hartmann's solution during and immediately after operation.

ABSORPTION IN CONTRAST STUDIES

Before operation the jejunum absorbed sodium and water (mean $\mathrm{Na}^{+}$absorption 0.27 m-equiv $/ 30 \mathrm{~cm} /$ $\min , \mathrm{H}_{2} \mathrm{O}$ absorption $1.56 \mathrm{ml} / 30 \mathrm{~cm} / \mathrm{min}$ ). The net transport of potassium varied from subject to subject and from aliquot to aliquot for any given subject. Six subjects demonstrated a mean absorption, while five subjects demonstrated a mean secretion. One subject showed no mean net transport of potassium (mean $\mathrm{K}^{+}$absorption 0.001 $\mathrm{m}$-equiv $/ 30 \mathrm{~cm} / \mathrm{min}$ ).

\section{PATIENTS RECEIVING INTRAVENOUS FLUIDS} When patients received intravenous fluids after vagotomy or cholecystectomy there was no significant change in the net absorption of sodium, water, or potassium. Absorption rates in both groups were less at 30 hours than at six hours and this difference was a little more pronounced in those undergoing cholecystectomy where the absorption of water was just significantly depressed at 30 hours $(P<0.05)$ but there was no significant difference between those patients who underwent vagotomy and those who underwent cholecystectomy.

There was no difference in the exchange of water and electrolytes across the intestinal mucosa between the contrast subjects and either group of postoperative patients. The postoperative handling of water and electrolytes by the vagotomized jejunum in patients receiving intravenous fluids was therefore 'normal'.

\section{PATIENTS NOT RECEIVING INTRAVENOUS} FLUIDS

When intravenous fluids were withheld from patients after cholecystectomy or vagotomy absorption of water and sodium was depressed and potassium was secreted. Six hours after operation sodium and 


\begin{tabular}{|c|c|c|c|c|c|c|c|c|c|}
\hline \multirow[t]{2}{*}{ Studies } & \multicolumn{3}{|c|}{ Sodium (m-equiv/30 cm/min) } & \multicolumn{3}{|c|}{ Potassium (m-equiv/30 cm/min) } & \multicolumn{3}{|c|}{ Water $(\mathrm{ml} / 30 \mathrm{~cm} / \mathrm{min})$} \\
\hline & Net & Out of Lumen & Into Lumen & Net & Out of Lumen & Into Lumen & Net & Out of Lumen & Into Lume \\
\hline $\begin{array}{l}\text { Contrast subjects } \\
\text { Six hours after } \\
\text { cholecystectomy }\end{array}$ & $0 \cdot 27 \pm 0 \cdot 1$ & $0.87 \pm 0.23$ & $0.60 \pm 0.15$ & $+0.0013 \pm 0.004$ & $0.025 \pm 0.01$ & $0.023 \pm 0.007$ & $1 \cdot 56 \pm 0.68$ & $9 \cdot 90 \pm 2 \cdot 4$ & $8 \cdot 32 \pm 2 \cdot 1$ \\
\hline $\begin{array}{l}\text { with iv fluids } \\
\text { Six hours after } \\
\text { vagotomy with iv }\end{array}$ & $0.38 \pm 0.02$ & $1.02 \pm 0.02$ & $0.64 \pm 0.05$ & $0.006 \pm 0.001$ & $0.03 \pm 0.015$ & $0.024 \pm 0.01$ & $2 \cdot 26 \pm 0 \cdot 21$ & $12 \cdot 07 \pm 0 \cdot 3$ & $9 \cdot 81 \pm 0 \cdot 16$ \\
\hline $\begin{array}{l}\text { fluids } \\
\text { Thirty hours after } \\
\text { cholecystectomy }\end{array}$ & $0.24 \pm 0.08$ & $0 \cdot 70 \pm 0 \cdot 29$ & $0.46 \pm 0.21$ & $0.001 \pm 0.002$ & $0.019 \pm 0.006$ & $0.018 \pm 0.007$ & $1 \cdot 32 \pm 0.048$ & $9 \cdot 12 \pm 3 \cdot 1$ & $7 \cdot 79 \pm 2 \cdot 6$ \\
\hline $\begin{array}{l}\text { with iv fluids } \\
\text { Thirty hours after } \\
\text { vagotomy with iv }\end{array}$ & $0 \cdot 18 \pm 0 \cdot 06$ & $0.54 \pm 0.07$ & $0.37 \pm 0.02$ & $0.003 \pm 0.001$ & $0.017 \pm 0.001$ & $0.015 \pm 0.001$ & $0.64 \pm 0.4$ & $8.59 \pm 0.62$ & 7. \\
\hline $\begin{array}{l}\text { fluids } \\
\text { Six hours after } \\
\text { cholecystectomy }\end{array}$ & $0.23 \pm 0.03$ & $0.84 \pm 0.22$ & $0.61 \pm 0.23$ & $-0.002 \pm 0.004$ & $0.024 \pm 0.007$ & $0.025 \pm 0.012$ & $1 \cdot 10 \pm 0 \cdot 35$ & $10 \cdot 06 \pm 3.5$ & $8.96 \pm 3 \cdot 7$ \\
\hline $\begin{array}{l}\text { without iv fluids } \\
\text { Six hours after } \\
\text { vagotomy without }\end{array}$ & $0 \cdot 142 \pm 0.05$ & $0 \cdot 54 \pm 0 \cdot 21$ & $0.55 \pm 0.17$ & $-0.003 \pm 0.003$ & $0.015 \pm 0.009$ & $0.016 \pm 0.010$ & $0.69 \pm 0.3$ & $8 \cdot 36 \pm 2 \cdot 6$ & $8 \cdot 34 \pm 2 \cdot 1$ \\
\hline $\begin{array}{l}\text { iv fluids } \\
\text { Thirty hours after } \\
\text { cholecystectomy }\end{array}$ & $0.16 \pm 0.01$ & $0.61 \pm 0.04$ & $0.45 \pm 0.04$ & $-0.007 \pm 0.005$ & $0.016 \pm 0.002$ & $0.024 \pm 0.003$ & $0.89 \pm 0.18$ & $11.63 \pm 1.4$ & $10 \cdot 82 \pm 1 \cdot 3$ \\
\hline $\begin{array}{l}\text { without iv fluids } \\
\text { Thirty hours after } \\
\text { vagotomy without }\end{array}$ & $0.012 \pm 0.07$ & $0.44 \pm 0 \cdot 19$ & $0.43 \pm 0.27$ & $-0.004 \pm 0.002$ & $0.012 \pm 0.0 c 8$ & $0.017 \pm 0.011$ & $-0.43 \pm 0.35$ & $10 \cdot 35 \pm 1 \cdot 3$ & $10 \cdot 79 \pm 1 \cdot 7$ \\
\hline $\begin{array}{l}\text { iv fluids } \\
\text { Patients with } \\
\text { 'normal' bowel }\end{array}$ & $0.011 \pm 0.03$ & $0.27 \pm 0.01$ & $0.26 \pm 0.04$ & $-0.006 \pm 0.002$ & $0.007 \pm 0.002$ & $0.014 \pm 0.002$ & $-0 \cdot 17 \pm 0 \cdot 27$ & $8 \cdot 08 \pm 1 \cdot 26$ & $8 \cdot 21 \pm 1$ \\
\hline $\begin{array}{l}\text { habit after vagotomy } \\
\text { Patients with post- }\end{array}$ & $0.33 \pm 0.08$ & $1 \cdot 15 \pm 0 \cdot 14$ & $0.83 \pm 0.08$ & $0.001 \pm 0.004$ & $0.03 \pm 0.002$ & $0.03 \pm 0.006$ & $2 \cdot 0 \pm 0 \cdot 8$ & $12 \cdot 7 \pm 0.6$ & $10 \cdot 7 \pm 0 \cdot 87$ \\
\hline vagotomy diarrhoea & $0.29 \pm 0.07$ & $1 \cdot 01 \pm 0.23$ & $0.70 \pm 0.19$ & $0.001 \pm 0.01$ & $0.30 \pm 0.01$ & $0.03 \pm 0.009$ & $1.68 \pm 0.37$ & $10 \cdot 56 \pm 2 \cdot 5$ & $8 \cdot 88 \pm 2 \cdot 3$ \\
\hline
\end{tabular}

Table Results recorded as mean \pm standard deviation

water absorption was significantly reduced; 30 hours after operation sodium absorption was greatly reduced and water was secreted. Potassium was secreted by both groups of patients but only in the case of those who underwent vagotomy was this significantly different from the contrast studies. There was, however, no significant difference in the net transport of potassium between the two groups of patients.

The two-way traffic of sodium and potassium across the jejunal mucosa was reduced in both directions at both six and 30 hours, being greater at 30 hours. There was little change in the two-way traffic for water in either group of postoperative patients.

The intestinal handling of water and electrolytes immediately after operation was similar in these two groups of patients and was not altered in any way by vagal denervation.

\section{LONG-TERM EFFECTS}

After the 10th postoperative day, three of the above patients who had undergone vagotomy were studied again. In all three cases insulin tests of gastric secretion were negative by Hollander's criteria (1948), indicating a complete truncal vagotomy and small gut denervation. These patients were well and taking a normal diet; they had noticed no change in bowel habit and have developed none since.

Three patients were studied who had severe postvagotomy diarrhoea. All of them had had a truncal vagotomy more than two years earlier; all had lost weight and were considerably incapacitated by the passage of watery motions daily. All these patients had negative insulin tests according to Hollander's criteria.

There was no significant difference in the intestinal handling of water and electrolytes between either of these groups of patients and the contrast subjects. The capacity of the jejunum to absorb water and electrolytes 'some time' after vagal denervation, therefore, was not impaired.

\section{Discussion}

We have studied the intestinal handling of water and electrolytes by the intact human jejunum before, immediately after, and 'some time' after truncal vagotomy. Immediately after operation absorption of water and electrolytes was depressed when the patients were deprived of intravenous fluids. The vagotomized jejunum at this time behaved like the vagally innervated jejunum.

It might be expected that any absorptive effects of 
vagotomy would be greatest immediately after vagal denervation, but it could be that any such effects are masked at this time by the more general 'intestinal response to surgery', which has previously been described (Bunch, 1971). The studies performed at varying intervals after vagotomy, however, do not confirm this. After 10 days the intestinal handling of water and electrolytes was similar to that observed in the contrast subjects and even when patients with severe postvagotomy diarrhoea were studied no impairment of absorption was detected.

It must be emphasized that this technique of studying absorption measures absorptive capacity: the suppression of intestinal motility below the occluding balloon (Phillips and Summerskill, 1966) means that the technique is largely 'motility independent'. Thus an increase in intestinal motility which may follow vagotomy (Alvarez, Hosoi, Overgard, and Ascanio, 1929; Collins, Crile, and Davis, 1948; Waddell and Wang, 1953; McKelvey, 1970) would allow a shorter contact time between the luminal contents and the mucosa, and may lead to decreased absorption in spite of a normal absorptive capacity.

There has been little interest in water and electrolyte absorption after vagotomy in spite of the obvious relationship between diarrhoea and fluid and electrolyte malabsorption. Tidball and Tidball (1955) suggested that the vagus had a stimulant effect on the net absorption of sodium and water from the ileum of the dog, and Berndt and Rech (1963) found an increased mesothelial permeability in guinea pigs after vagotomy. In this present study we have found no evidence for any vagal influence on net absorption, nor was the two-way traffic for water and electrolytes altered by vagotomy.

In a clinical study Cox (1962) introduced radioactive sodium iodine $\left(\mathrm{Na}^{131} \mathrm{I}\right)$ into the intestine and measured the equilibration of the absorbed radioactive iodine in the peripheral blood. His studies were performed before operation, 18 hours after operation, and one week after operation. There was some delay in equilibration 18 hours after operation but this had returned to normal after one week. In Cox's studies the absorption of a minor anion was measured, and it is unlikely that the rather specialized iodide ion gives any real indication of major electrolyte absorption, even though Cox's findings agree with our own.

The cause of postvagotomy diarrhoea remains obscure. It would seem, however, that whatever its cause the vagally denervated small intestine is quite capable of absorbing water and electrolytes at a normal rate if other factors permit it to do so.

\section{References}

Alvarez, W. C., Hosoi, K., Overgard, A., and Ascanio, H. (1929). The effects of degenerative section of the vagi and the spanchnics on the digestive tract. Amer. J. Physiol., 90, 631-655.

Berndt, W. O., and Rech, R. H. (1963). Altered mesothelial permeability in the guinea pig following bilateral vagotomy. Proc. Soc. exp. Biol. (N.Y.), 112, 950-953.

Bunch, G. A. (1971). The intestinal response to surgery. Brit. J. Surg., 58, 755-759.

Bunch, G. A., and Shields, R. (1969). Absorption of water and electrolytes by the human small intestine after surgical operations. Brit. J. Surg., 56, 708.

Code, C. F., and McIntire F. C. (1956). Quantitative determination of histamine. Meth. biochem. Anal., 3, 49-95.

Collins, E. N., Crile, G., Jr., and Davis, J. B. (1948). Follow-up of vagotomy plus gastroenterostomy or pyloroplasty for ulcer. Gastroenterology, 11, 453-456.

Cox, A. G. (1962). Small-intestinal absorption before and after vagotomy in man. Lancet, 2, 1075-1077.

Hollander, F. (1948). Laboratory procedures in the study of vagotomy, with particular reference to the insulin test. Gastroenterology, 11, 419-425.

McKelvey, S. T. D. (1970). Gastric incontinence and post-vagotomy diarrhoea. Brit. J. Surg., 57, 741-747.

Phillips, S. F., and Summerskill, W. H. J. (1966). Occlusion of the jejunum for intestinal perfusion in man. Mayo Clin. Proc., 41, 224-231.

Phillips, S. F., and Summerskill, W. H. J. (1966). Water and electrolyte transport during maintenance of isotonicity in human jejunum and ileum. J. Lab. clin. Med., 70, 686-698.

Shields, R. (1966). Absorption and secretion of electrolytes and water by the human colon, with particular reference to benign adenoma and papilloma. Brit. J. Surg., 53, 893-897.

Tidball, C. S., and Tidball, M. E. (1955). Changes in intestinal net absorption produced by atropine and vagotomy. Amer. J. Physiol., 183, 667.

Waddell, W. R., and Wang, C. C. (1953). Effect of vagotomy on gastric evacuation of high fat meals. J. appl. Physiol., 5, 705-711. 